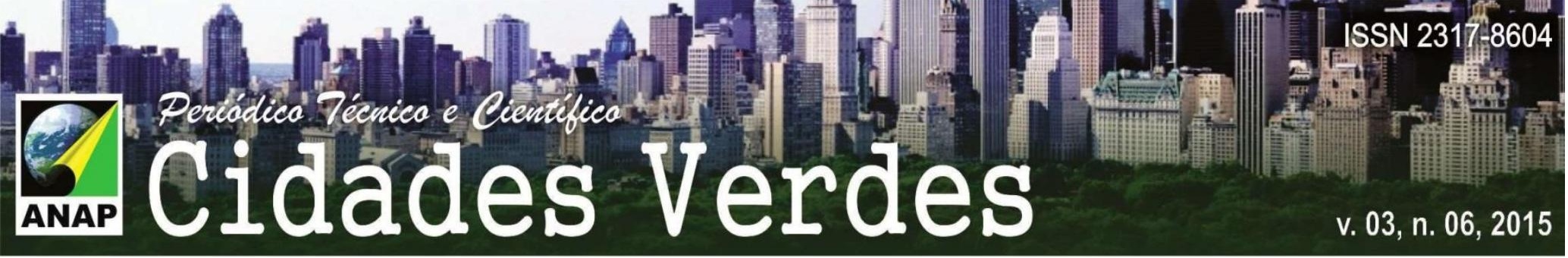

Titulo do Trabalho

\title{
CONSTRUÇÃO EMPRESARIAL SUSTENTÁVEL: APLICAÇÃO NO SETOR BANCÁRIO - AGÊNCIA VERDE.
}

Nome do Autor (a) Principal

Thais Aghat Magalhães Orestes

Instituição ou Empresa

Universidade Estadual Paulista - UNESP - Faculdade de Ciências e Tecnologia

- Campus Presidente Prudente

Instituição (s) de Fomento

E-mail de contato

thais_aghat@hotmail.com

Palavras-chave

Consultoria; Sustentável; dados estatísticos; Agência Bancária.

INTRODUÇÃO

O desafio da sustentabilidade assumiu, há alguns anos, um papel de destaque na indústria da Construção no Brasil. O setor está cada vez mais consciente sobre a relevância do seu papel no contexto da mitigação e adaptação dos efeitos das mudanças climáticas e da necessidade de melhoria das condições de vida no planeta.

Apesar de sua indiscutível importância para o desenvolvimento do país, a construção civil é apontada como uma das indústrias que mais impactam o meio ambiente. Para se ter uma ideia, o setor consome 2/3 da madeira natural e cerca de $50 \%$ dos recursos naturais do planeta, sendo grande parte de recursos não 
renováveis. Além da extração, o processo produtivo também é bastante nocivo. A fabricação de cimento, por exemplo, é responsável por $8 \%$ do total.

A cadeia produtiva da Construção Civil tem uma novo desafio a cumprir. As mudanças climáticas e a escassez de recursos naturais exigem novas formas de organização empresarial e política.

O modelo a ser buscado pelo setor é o do desenvolvimento humano, da inovação tecnológica e do uso e reuso equilibrado de recursos disponíveis, bem como da reciclagem. Tal transformação exige mudanças em termos de regulamentação, mercado, precificação de produtos e insumos e mensuração de lucros e perdas.

Mudanças essas que se tornarão realidade na medida em que passarmos a encarar os desafios da cadeia produtiva da construção não mais sob uma lógica de custos, mas de oportunidades.

No Brasil o setor da construção civil a partir da perspectiva social é o termômetro do desenvolvimento do país e gera, atualmente, segundo a Câmara Brasileira da Indústria da Construção (CBIC), mais de 2,6 milhões de empregos diretos. Na perspectiva econômica, sua cadeia produtiva é responsável por cerca de $15 \%$ do nosso PIB.

Há, ainda, o contexto da administração, o de um modelo de sustentabilidade corporativa. Neste caso, a gestão se dá da mesma forma que qualquer empresa de outro setor. Estamos falando de processos estruturados de forma sustentável. O desafio aqui é o desenvolvimento de ações de infraestrutura que convirjam os esforços para o empreendimento de processos e práticas que sejam precursoras, multiplicadoras, demonstrativas ou exemplares em termos de responsabilidade socioambiental.

\section{OBJETIVO}

O objetivo consiste em propor a construção de uma agência bancária "Verde", onde a sustentabilidade seja aplicada não somente no método de 
Desta forma o trabalho propõe desenhar ações eficazes com uma análise abrangente, sistêmica da construção de agências bancárias, focando em aplicação viável.

\section{METODOLOGIA}

A metodologia a ser utilizada baseia-se no estudo estatístico e confecção de consultoria para construção de uma agência sustentável, relacionando os impactos financeiros e recuperação através de análises do processo de inovação concebido posteriormente pelo pai da inovação Joseph Shumpter que entendia "[O que conta] é a concorrência pelo novo bem de consumo, nova tecnologia, nova fonte de fornecimento, novo tipo de organização... concorrência que não atinge a margem dos lucros e dos resultados das empresas existentes, mas os seus fundamentos e suas próprias vidas." (TIDD; BESSANT, apud PAVITT, 2008, pag.27).

Assim de acordo com o cronograma pretende-se executar os seguintes itens:

\begin{tabular}{|l|l|l|l|l|l|l|}
\hline $\begin{array}{l}\text { Fases da } \\
\text { pesquisa } \\
\text { (Atividades) }\end{array}$ & Período 1 & Período 2 & Período 3 & Período 4 & Período 5 & Período 6 \\
\hline $\begin{array}{l}\text { Elaboração de } \\
\text { Premissas }\end{array}$ & $\mathrm{x}$ & $\mathrm{x}$ & & & & \\
\hline $\begin{array}{l}\text { Elaboração de } \\
\text { Arte para } \\
\text { "Agencia } \\
\text { Verde" }\end{array}$ & $\mathrm{x}$ & & $\mathrm{x}$ & & & \\
\hline $\begin{array}{l}\text { Elaboração da } \\
\text { consultoria. }\end{array}$ & $\mathrm{x}$ & $\mathrm{x}$ & $\mathrm{x}$ & $\mathrm{x}$ & $\mathrm{x}$ & $\mathrm{x}$ \\
\hline $\begin{array}{l}\text { Analise de } \\
\text { Dados }\end{array}$ & $\mathrm{x}$ & $\mathrm{x}$ & $\mathrm{x}$ & $\mathrm{x}$ & $\mathrm{x}$ \\
\hline $\begin{array}{l}\text { (Elaboração de } \\
\text { Projetos } \\
\text { Arquitetônico, } \\
\text { estrutural, } \\
\text { elétrico e civil) }\end{array}$ & & & & $\mathrm{x}$ & $\mathrm{x}$ & $\mathrm{x}$ \\
\hline
\end{tabular}

Fazendo-se necessário o atendimento das seguintes premissas norteando o cronograma apresentado: 
- $\quad$ Priorizar edificações sustentáveis.

- Implantar processos sustentáveis para os imóveis de uso.

- Incorporar itens de sustentabilidade no planejamento de projetos, construções, reformas e manutenção de todos os imóveis de uso.

- $\quad$ Promover o consumo sustentável de recursos naturais e de materiais nos processos internos.

- $\quad$ Promover a redução do consumo e dispêndio com água e energia elétrica nas dependências da empresa.

- Garantir instalações modernas, adequadas e o com livre acesso às pessoas portadoras de deficiência ou com mobilidade reduzida.

- Garantir ambientes padronizados, confortáveis, ergonômicos e ecoeficientes.

- Incentivar o uso de energias renováveis e inovações tecnológicas que promovam a eficiência da edificação.

\section{CONCLUSÃO}

A história tem mostrado que a estrada da inovação tecnológica é cheia de obstáculos. E inovar com sustentabilidade parece ser o desafio do presente século. Essa jornada também é complexa e cheia de idas e vindas.

Não é da noite para o dia que uma sociedade conseguirá migrar das tecnologias antigas para as consideradas inovadoras e sustentáveis. Mas as portas estão abertas e empresas já olham para o mercado das tecnologias verdes com bons olhos. Os consumidores também estão sensíveis e atentos à procura de produtos e serviços que causem menos impactos negativos ao meio ambiente, à sociedade e à economia.

Um grande setor inexplorado e na busca pela sustentabilidade é o da Construção Civil, responsável pelo consumo de muitos recursos naturais do planeta, desde a extração de matéria-prima até o fim da vida útil. Por outro lado, enquanto a fase de construção tem alavancado um setor gigantesco de matéria prima sustentável, este setor ainda novo manifesta-se inviável financeiramente para setor 


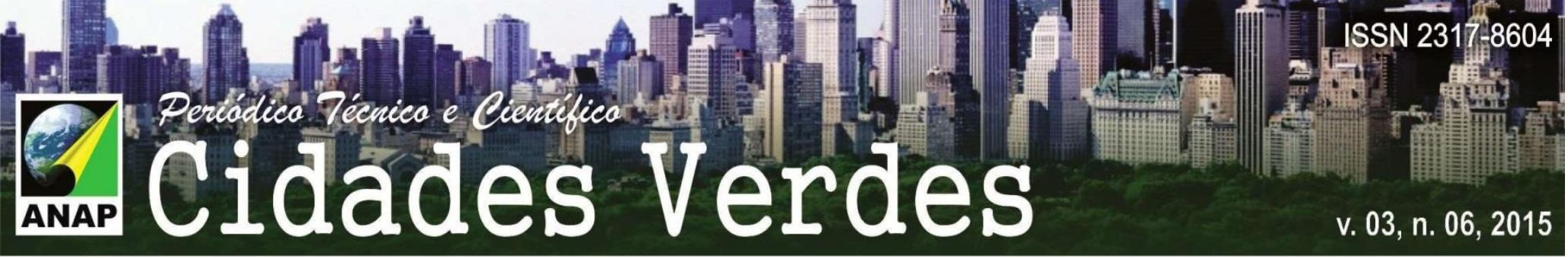

empresarial sem auxílio e incentivo à pesquisas e análise de dados (visando retorno/ganho).

\section{REFERÊNCIAS}

BACHA, Maria de Lourdes; SANTOS, Jorgina. SCHAUN, Angela. Considerações teóricas sobre o Conceito de Sustentabilidade. ANAIS... VII SEGeT - Simpósio de Excelência em Gestão e Tecnologia, 2010.

GOLDEMBERG José (coord); AGOPYAN Vahan JOHN Vanderley M. John. O Desafio da Sustentabilidade na Construção Civil. Blucher, 2011.

Câmara Brasileira da Indústria Construção. Desenvolvimento com Sustentabilidade.

ANTUNES, Julianna. Um Olhar Sustentável sobre O Mundo Empresarial. Disponível em: http://www.sustentabilidadecorporativa.com.

MUNIZ FILHO, Martiniano Ribeiro Muniz Filho. Sustentabilidade na Construção de Agências da Caixa. ANAIS... 4ํㅗㅇ Simpósio Brasileiro de Construção Civil, 2011.

Almeida, Fernando A. O Bom Negócio da Sustentabilidade. Nova Fronteira: 2002. 